\title{
Experience with inhaled iloprost and bosentan in portopulmonary hypertension
}

\author{
M.M. Hoeper*, H.J. Seyfarth\#, G. Hoeffken ${ }^{\top}$, H. Wirtz" ${ }^{\#}$ E. Spiekerkoetter*, \\ M.W. Pletz*, T. Welte* and M. Halank
}

ABSTRACT: Novel treatments, such as prostanoids or endothelin receptor antagonists, have been introduced for various forms of pulmonary arterial hypertension, but the long-term effects of these treatments on portopulmonary hypertension (PPHT) are unknown.

In a retrospective analysis, the present authors assessed the safety and efficacy of inhaled iloprost, a prostacyclin analogue, and bosentan, an endothelin receptor antagonist, in patients with PPHT. In total, 31 consecutive patients with Child class A or B cirrhosis and severe PPHT were treated for up to 3 yrs with either inhaled iloprost $(n=13)$ or bosentan $(n=18)$, and the effects on exercise capacity, haemodynamics and survival were evaluated.

In the iloprost group, the survival rates at 1, 2 and 3 yrs were 77,62 and $46 \%$, respectively. In the bosentan group, the respective survival rates were 94, 89 and $89 \%$. Event-free survival rates, i.e. survival without transplantation, right heart failure or clinical worsening requiring the introduction of a new treatment for pulmonary hypertension, was also significantly better in the bosentan group. Bosentan had significantly better effects than inhaled iloprost on exercise capacity, as determined by the 6-min walk test, as well as on haemodynamics. Both treatments proved to be safe, especially in regards of liver function.

In the present series of patients with well-preserved liver function and severe portopulmonary hypertension, treatment with both inhaled iloprost and bosentan appeared to be safe. Patients treated with bosentan had higher survival rates, but prospective controlled studies are required to confirm these findings.

KEYWORDS: Bosentan, cirrhosis, iloprost, portopulmonary hypertension, pulmonary hypertension

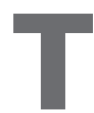
he term portopulmonary hypertension (PPHT) refers to the development of pulmonary arterial hypertension $(\mathrm{PAH})$ in patients with portal hypertension, a rare but serious complication occurring in $1-2 \%$ of patients with cirrhosis [1, 2]. Affected patients typically complain of progressive dyspnoea on exertion and may show signs of right heart dysfunction. Left untreated, PPHT carries a poor prognosis with $1-y r$ mortality rates ranging between 24 and $60 \%[3,4]$.

Treatment of PPHT has never been assessed in randomised clinical trials, especially since this group of patients has been excluded from almost all large clinical studies that have been performed in the field of PAH. Case reports and smaller case series suggest that treatments that are effective in other forms of $\mathrm{PAH}$, i.e. prostanoids, phosphodiesterase-5 inhibitors and endothelin receptor

For editorial comments see page 1038. antagonists, may also be beneficial in patients with PPHT [5-7]. The long-term safety and effectiveness of these treatments in PPHT, however, have never been evaluated.

In the present study, the 3-yr experience with two substances, bosentan, an endothelin receptor antagonist, and inhaled iloprost, a prostanoid, was assessed in patients with PPHT. Preliminary data including some of these patients have already been presented in previous publications, but the present study, for the first time, evaluated the effects of the two treatments for an extended period of time [7-10].

\section{PATIENTS AND METHODS}

A retrospective cohort study of patients with cirrhosis and PPHT who started treatment with either inhaled iloprost or bosentan between 1999 and 2004 was performed. The analysis was based on medical record reviews. This study enrolled all but two patients with PPHT who were seen at
AFFILIATIONS

*Dept of Respiratory Medicine, Hannover Medical School, Hannover, \#Dept of Respiratory Medicine, University of Leipzig, Leipzig, and "Dept of Internal Medicine I, CarlGustav-Carus University Dresden, Dresden, Germany.

\section{CORRESPONDENCE}

M.M. Hoeper

Dept of Respiratory Medicine

Hannover Medical School

30623 Hannover

Germany

Fax: 495115328536

E-mail: hoeper.marius@mh-

hannover.de

Received:

May 172007

Accepted after revision:

July 112007

STATEMENT OF INTEREST

Statements of interest for M.M. Hoeper, H.J. Seyfarth, G. Hoeffken, H. Wirtz and M. Halank can be found at www.erj.ersjournals.com/misc/ statements.shtml 
the participating centres during the indicated time period, regardless of their Child class. The two patients not included suffered from alcoholic cirrhosis and psychotic disorders, and were felt to be too noncompliant; no specific pharmacotherapy for pulmonary hypertension was instituted.

No medication has been explicitly approved for PPHT in Europe. All patients were informed about this fact and consented to both treatment and the scientific evaluation of their data. This approach and the present study were approved by the institutional review board of the participating centres.

The choice between bosentan or iloprost treatment was neither randomised nor stratified and was based on the preferences of the patients and their physicians. Iloprost was given six times daily at a dose of $5 \mu \mathrm{g}$ at the mouthpiece using standard nebulisers. Bosentan was started at a dose of $62.5 \mathrm{mg}$ b.i.d. for 4 weeks followed by $125 \mathrm{mg}$ b.i.d. as target maintenance dose. Liver aminotransferases were monitored at 4-weekly intervals and comprehensive evaluations of laboratory results were performed 2-3 times per year. Elevated aminotransferase levels were managed according to the recommendations in the bosentan summary of product characteristics.

All patients were seen regularly for follow-up examinations at the outpatient clinics of their university hospitals in 34 monthly intervals. Follow-up investigations included the previously mentioned laboratory tests, as well as assessment of functional class, 6-min walk test, pulmonary function testing and blood gas analysis. Right heart catheterisations were performed at baseline in all patients and during irregular follow-up intervals, as determined by the clinical situation. All haemodynamic assessments were carried out in the morning before patients took their medication.

\section{Analysis}

All data are expressed as mean $\pm \mathrm{SD}$. Differences between the two groups at baseline were assessed by Mann-Whitney rank sum test for continuous variables and by Fisher's exact test for categorical variables. For the analysis of within-group changes, the Wilcoxon signed-rank test was used, whereas betweengroup changes were analysed with the Mann-Whitney U-test. Severity of liver disease was expressed by the Child class and by the Model End-stage Liver Disease (MELD) score [11, 12]. In patients receiving oral anticoagulants, an international normalised ratio value of 1.2 was used for calculation of Child class and MELD score.

The primary study outcome was survival; secondary outcomes included event-free survival, haemodynamics, functional class, 6-min walk distance and safety. There was no a priori hypothesis on the superiority of one treatment over the other. Overall survival and event-free survival (i.e. survival without transplantation or clinical deterioration requiring the introduction of a new compound for the treatment of pulmonary hypertension) were estimated using the Kaplan-Meier method and differences were evaluated with a stratified log-rank test. The Cox proportional hazard analysis was used to adjust for known prognostic factors. The cut-off date for all analyses was set for individual patients at 36 months after treatment with either inhaled iloprost or bosentan was started, or on October 31, 2006, for patients who had not completed the 36-month observation period at that time. For all analyses, a p-value $<0.05$ was considered statistically significant.

\section{RESULTS}

In total, 13 patients were treated with inhaled iloprost (Hannover, $\mathrm{n}=8$; Leipzig, $\mathrm{n}=4$; and Dresden, $\mathrm{n}=1$ ) and 18 with bosentan (Hannover, $n=13$; Leipzig, $n=2$; and Dresden, $n=3)$. The baseline characteristics of these patients are shown in table 1 . The most common underlying liver disease was alcoholic cirrhosis and the vast majority of patients presented in Child class A. All patients suffered from severe PPHT according to a recent definition $[1,13]$ and there were no significant differences at baseline between both groups in severity of the underlying liver disease, functional class, 6min walk distance and haemodynamics. There were no correlations between the severity of liver disease, as

\section{TABLE 1 Baseline characteristics of the patients under study}

lloprost group Bosentan group p-value

\begin{tabular}{|c|c|c|c|}
\hline Subjects $n$ & 13 & 18 & \\
\hline Female/male $n$ & $8 / 5$ & $9 / 9$ & 0.717 \\
\hline NYHA II & $1(8)$ & $0(0)$ & 0.419 \\
\hline NYHA III & $12(92)$ & $16(89)$ & 1.0 \\
\hline NYHA IV & $0(0)$ & $2(11)$ & 0.497 \\
\hline Age yrs & $44 \pm 8$ & $48 \pm 11$ & 0.144 \\
\hline 6-min walk distance $\mathrm{m}$ & $343 \pm 116$ & $358 \pm 101$ & 0.435 \\
\hline RAP $\mathrm{mmHg}$ & $6 \pm 5$ & $9 \pm 6$ & 0.204 \\
\hline $\bar{P}_{\text {pa }} \mathbf{m m H g}$ & $51 \pm 7$ & $52 \pm 7$ & 0.832 \\
\hline CO L. $\min ^{-1}$ & $4.9 \pm 1.6$ & $4.6 \pm 1.3$ & 0.735 \\
\hline $\mathrm{CI} \mathrm{L} \cdot \mathrm{min}^{-1} \cdot \mathrm{m}^{-2}$ & $2.6 \pm 0.6$ & $2.4 \pm 0.6$ & 0.352 \\
\hline PVR dyn's $\mathrm{cm}^{-5}$ & $812 \pm 337$ & $866 \pm 422$ & 0.866 \\
\hline $\mathrm{Sv}, \mathrm{O}_{2} \%$ & $65 \pm 9$ & $62 \pm 8$ & 0.204 \\
\hline FVC \% pred & $94 \pm 15$ & $92 \pm 17$ & 0.882 \\
\hline FEV $_{1} \%$ VC & $75 \pm 6$ & $73 \pm 10$ & 0.250 \\
\hline DL,Co \% pred & $68 \pm 16$ & $60 \pm 17$ & 0.209 \\
\hline $\mathrm{Pa}_{\mathrm{a}, \mathrm{O}_{2}} \mathrm{mmHg}$ & $79 \pm 13$ & $66 \pm 9$ & 0.002 \\
\hline $\mathrm{Pa}, \mathrm{CO}_{2} \mathrm{mmHg}$ & $31 \pm 3$ & $32 \pm 4$ & 0.767 \\
\hline \multicolumn{4}{|l|}{ Aetiology of cirrhosis } \\
\hline Alcoholic & $6(46)$ & $11(61)$ & 0.481 \\
\hline Viral hepatitis & $2(15)$ & $3(17)$ & 1.0 \\
\hline Autoimmune & $4(31)$ & $2(11)$ & 0.208 \\
\hline Other & $1(8)^{\#}$ & $2(11)^{\bullet}$ & 1.0 \\
\hline Child A & $10(77)$ & $18(100)$ & 0.064 \\
\hline Child B & $3(23)$ & $0(0)$ & 0.064 \\
\hline MELD score & $12 \pm 3$ & $10 \pm 3$ & 0.09 \\
\hline
\end{tabular}

Data are presented as $n(\%)$ or mean $\pm \mathrm{SD}$, unless otherwise indicated. NYHA New York Heart Association; RAP: right atrial pressure; $\bar{P}_{\text {pa: }}$ mean pulmonary artery pressure; $\mathrm{CO}$ : cardiac output; $\mathrm{Cl}$ : cardiac index; PVR: pulmonary vascular resistance; $\mathrm{SV}_{1} \mathrm{O}_{2}$ : mixed venous oxygen saturation; $\mathrm{FVC}$ : forced vital capacity; \% pred: \% predicted; FEV1: forced expiratory volume in one second VC: vital capacity; $\mathrm{DL}, \mathrm{CO}$ : diffusion capacity of the lungs for carbon monoxide $\mathrm{Pa}_{\mathrm{a}} \mathrm{O}_{2}$ : arterial oxygen tension; $\mathrm{Pa}_{\mathrm{a}} \mathrm{CO}_{2}$ : arterial carbon dioxide tension; MELD: Model End-stage Liver Disease. * : bile duct atresia; ": one cryptogenic and one idiopathic portal vein thrombosis. The MELD score is a disease severity score in patients with cirrhosis (see text for details). $1 \mathrm{mmHg}=0.133 \mathrm{kPa}$. 
expressed by the MELD score, and variables reflecting severity of pulmonary hypertension, such as 6-min walk distance, right atrial pressure, mean pulmonary arterial pressure, cardiac index and pulmonary vascular resistance (data not shown).

\section{Outcome}

During the 3-yr observation period, 10 patients died, eight in the iloprost group and two in the bosentan group. Six of the eight deaths in the iloprost group were caused by right heart failure; one patient died from variceal bleeding (Child class A at baseline) and one patient died after combined liver and lung transplantation (Child class B at baseline).

Out of the two patients who died in the bosentan group, one died from right heart failure and one from progressive liver failure (Child class A at baseline). The patient who died from right heart failure suffered from alcoholic cirrhosis with severe PPHT and presented in functional class IV at baseline. The initial response to bosentan treatment was excellent and the patient was in functional class II 3 months later. He was then lost to follow-up, but was readmitted 6 months later, again presenting in functional class IV with advanced heart and kidney failure. The patient reported that he had started drinking alcohol again and that he had stopped taking bosentan several weeks earlier. He died from multi-organ failure a few days later. The patient who died from liver failure suffered from cryptogenic cirrhosis and was in Child class A when PPHT was diagnosed. Dyspnoea improved with bosentan treatment, but one year later the patient presented with progressive hepatic dysfunction. Bosentan was discontinued but the patient died within 1 month from liver failure. His caregivers felt it unlikely that bosentan had contributed to liver failure because aminotransferase levels had been in the normal range at all times during bosentan exposure.

In the iloprost group, the survival rates at 1,2 and 3 yrs were 77,62 and $46 \%$, respectively. In the bosentan group, the respective survival rates were 94,89 and $89 \%$, respectively. The difference between both groups was statistically significant ( $p=0.029$ by log-rank analysis; fig. 1a).

Event-free survival rates, i.e. survival without transplantation, right heart failure or clinical worsening requiring the introduction of a new treatment for pulmonary hypertension, was also significantly better in the bosentan group $(\mathrm{p}=0.017$ by log-rank analysis). Among the 13 patients who started on inhaled iloprost, only three (23\%) continued this treatment for the entire 3-yr observation period without clinical worsening; one patient died before treatment was changed, and one patient underwent combined liver and lung transplantation but died 6 months later from a ruptured splenic artery aneurysm. Five patients required transition to intravenous prostacyclin treatment; four of them died 1, 2, 3 and 6 months later, respectively, and one patient survived until the end of the observation period ( 24 months after transition from inhaled to intravenous iloprost). Four patients had bosentan added to their medication (one of them was transitioned to bosentan for convenience while being stable on iloprost treatment for 2 yrs; for the purposes of this analysis, this patient was considered stable on iloprost for the whole observation period); three of these patients were alive at the end of the observation period and one died after 27 months.

Among the 18 patients who started on bosentan, 14 (78\%) patients continued treatment throughout the observation period without a clinical event. Two patients required addition of sildenafil because of clinical worsening; both patients had functional improvement (6-min walk distance improved by 10 and $62 \mathrm{~m}$ after 3 months, respectively) and survived until the end of the follow-up period. As described above, two patients died. None of the patients in the bosentan group had to be transitioned to intravenous prostacyclin treatment and none required transplantation. The Kaplan-Meier curves for eventfree survival of both groups are depicted in figure $1 \mathrm{~b}$.

\section{Cox proportional hazard analysis}

The Cox proportional hazard analysis was performed to adjust for baseline factors that may have influenced the present
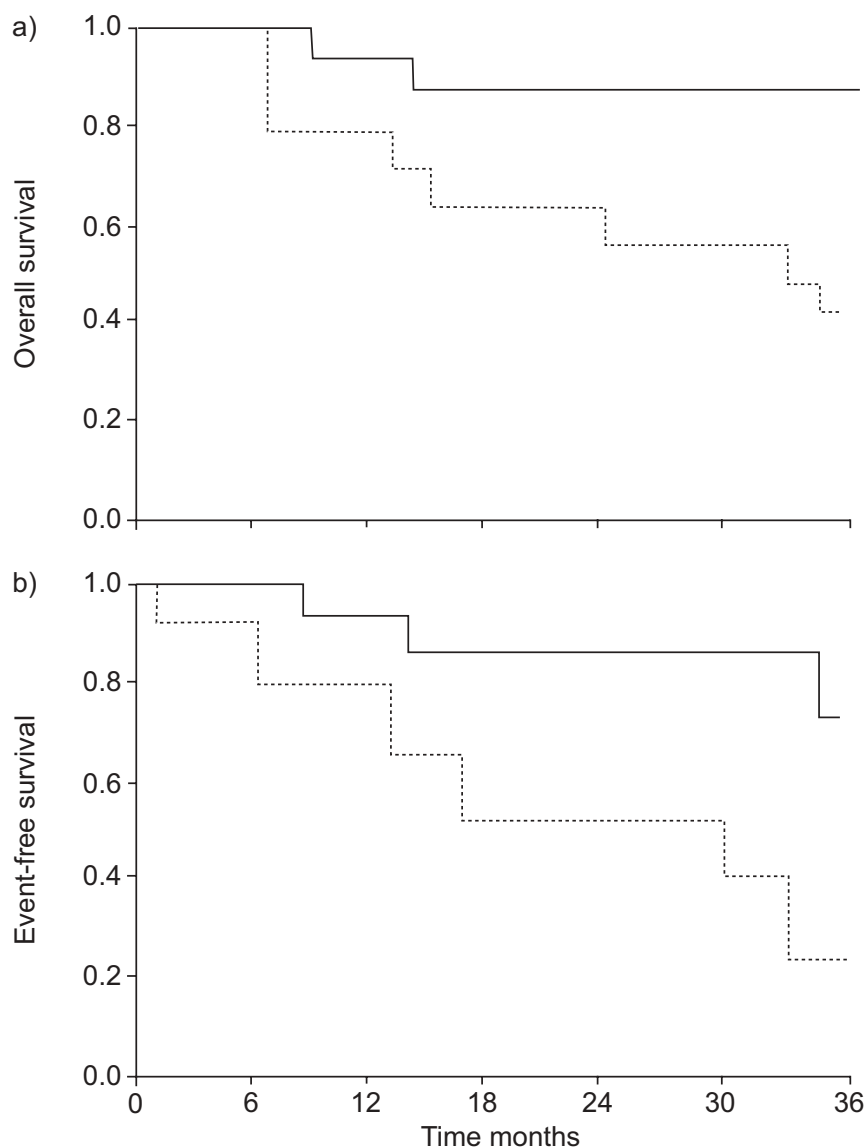

FIGURE 1. a) Overall survival and b) event-free survival of patients with portopulmonary hypertension treated with bosentan $(-)$ or inhaled iloprost $(\cdots \cdots \cdots . .$.$) are shown. Events were deaths, transplantation or clinical worsening$ requiring the introduction of a new treatment for pulmonary hypertension. The number of subjects at risk were as follows. a) Bosentan group: $n=18,18,17,16,14$, 14 and 11 at $0,6,12,18,24,30$ and 36 months, respectively. Iloprost group: $n=13$, $13,10,8,8,7$ and 6 at $0,6,12,18,24,30$ and 36 months, respectively. b) Bosentan group: $n=18,18,17,16,14,14$ and 9 at $0,6,12,18,24,30$ and 36 months, respectively. Iloprost group: $n=13,12,10,6,6,6$ and 2 at $0,6,12,18,24,30$ and 36 months, respectively. a) $p=0.029$; b) $p=0.017$. 


\begin{tabular}{|c|c|c|c|}
\hline TABLE 2 & \multicolumn{3}{|c|}{$\begin{array}{l}\text { Multivariate Cox proportional hazard analysis } \\
\text { relating survival time to selected variables } \\
\text { potentially linked to outcome }\end{array}$} \\
\hline Variables & & $\begin{array}{l}\text { Hazard ratio (95\% } \\
\text { confidence interval) }\end{array}$ & p-value \\
\hline \multicolumn{2}{|c|}{ 6-min walk distance } & $0.998(0.992-1.005)$ & 0.557 \\
\hline \multicolumn{2}{|c|}{ Right atrial pressure } & $1.070(0.940-1.218)$ & 0.305 \\
\hline \multicolumn{2}{|c|}{ MELD score } & $0.473(0.073-3.060)$ & 0.432 \\
\hline \multicolumn{2}{|c|}{$\begin{array}{l}\text { Iloprost versus } \\
\text { bosentan }\end{array}$} & $6.103(1.039-35.859)$ & 0.045 \\
\hline \multicolumn{4}{|c|}{$\begin{array}{l}\text { The Model End-stage Liver Disease (MELD) score is a disease severity score in } \\
\text { patients with cirrhosis (see text for details). Right atrial pressure and 6-min walk } \\
\text { distance were input as continuous variables, whereas MELD score and } \\
\text { medication were input as categorical variables. }\end{array}$} \\
\hline
\end{tabular}

findings. Two different types of analyses were performed, a primary analysis adjusted for variables of known prognostic significance and a secondary stepwise variable selection to support the findings of the adjusted analysis. With the primary analysis including the variables medication, MELD score, Child class, New York Heart Association class, 6-min walk distance, right atrial pressure, mean pulmonary artery pressure, cardiac output, cardiac index, pulmonary vascular resistance and mixed venous oxygen saturation, only mediation was significantly associated with survival $(\mathrm{p}=0.021)$. With multivariate analysis including right atrial pressure/6-min walk distance as continuous variables and MELD score/ medication as categorical variables, only medication was significantly associated with survival (table 2).

\section{Haemodynamic assessment}

Assessment of the haemodynamic changes in both treatment groups was hampered by the high incidence of clinical worsening in the iloprost-treated patients and the resulting high dropout rate in this group. Therefore, the analysis of haemodynamic parameters was restricted to changes in haemodynamics between the baseline examination and the first follow-up catheterisation, which took place 3-18 months after treatment was initiated $(8 \pm 4$ months in the iloprost group and $10 \pm 5$ months in the bosentan group). For this time frame, data were available for 11 patients in the iloprost group and 13 patients in the bosentan group. As shown in table 3 and figure 2, in the iloprost group, there were no significant changes in right atrial pressure, mean pulmonary arterial pressure, cardiac output, pulmonary vascular resistance and mixed venous oxygen saturation. In contrast, all these haemodynamic variables improved substantially in bosentantreated patients.

\section{Functional assessment}

Patients who started on iloprost were in functional class II $(n=1)$ or III $(n=12)$ at baseline. After 1 yr of treatment, three patients had died; out of the remaining 10 patients, four were in functional class II, five in functional class III, and one in functional class IV. Out of the five patients who were alive after 3 yrs, two were in functional class II, two in class III and one in class IV at that time.

Among the patients who started on bosentan, 16 were in functional class III and two in functional class IV at baseline. After $1 \mathrm{yr}$ of treatment, one patient had died, 12 were in functional class II and five in functional class III. Out of the 10 patients who completed 3-yr follow-up, six presented in functional class II and four in class III at that time.

Among the 10 iloprost-treated patients who could be assessed after $1 \mathrm{yr}$ of treatment, the 6-min walking distance increased from $367 \pm 109 \mathrm{~m}$ at baseline to $406 \pm 125 \mathrm{~m}$ after $1 \mathrm{yr}$ (mean difference $+44 \mathrm{~m} ; \mathrm{p}=0.278$ ). However, after 3 yrs, functional improvement was maintained in only three patients.

Among the 17 assessable patients in the bosentan group, the 6min walk distance increased from $377 \pm 64 \mathrm{~m}$ at baseline to $448 \pm 60 \mathrm{~m}$ after $1 \mathrm{yr}$ (mean difference $+70 \mathrm{~m} ; \mathrm{p}<0.001$ versus

TABLE 3 Haemodynamic changes from baseline to the first follow-up catheterisation (3-18 months) in patients with portopulmonary hypertension treated with inhaled iloprost or bosentan

\begin{tabular}{|c|c|c|c|c|c|}
\hline & \multicolumn{2}{|c|}{ lloprost ${ }^{\#}$} & \multicolumn{2}{|c|}{ Bosentan } & \multirow{2}{*}{$\begin{array}{l}\text { Between group } \\
\text { difference }\end{array}$} \\
\hline & Baseline & 6-18 months & Baseline & 6-18 months & \\
\hline RAP $\mathrm{mmHg}$ & $7 \pm 6$ & $11 \pm 8$ & $8 \pm 6$ & $4 \pm 3$ & $D=0.040$ \\
\hline Change (p-value) & \multicolumn{2}{|c|}{$4 \pm 11(p=0.320)$} & \multicolumn{2}{|c|}{$-4 \pm 5(p=0.027)$} & $p=0.040$ \\
\hline $\bar{P}$ pa $\mathrm{mmHg}$ & $50 \pm 10$ & $53 \pm 8$ & $53 \pm 8$ & $45 \pm 13$ & $n=0.077$ \\
\hline Change ( $p$-value) & \multicolumn{2}{|c|}{$0 \pm 1.8(p=0.765)$} & \multicolumn{2}{|c|}{$1.2 \pm 1.1(p=0.002)$} & $p=0.060$ \\
\hline PVR dyn & $828 \pm 349$ & $895 \pm 351$ & $925 \pm 473$ & $579 \pm 261$ & $p=0.022$ \\
\hline Change ( $p$-value) & \multicolumn{2}{|c|}{$73 \pm 457(p=0.413)$} & \multicolumn{2}{|c|}{$-345 \pm 361(p=0.008)$} & $p=-0.0<2$ \\
\hline $\mathrm{Sv}, \mathrm{O}_{2} \%$ & $65 \pm 9$ & $62 \pm 11$ & $61 \pm 7$ & $68 \pm 5$ & $n=0,06$ \\
\hline Change (p-value) & \multicolumn{2}{|c|}{$-3 \pm 13(p=0.966)$} & \multicolumn{2}{|c|}{$6 \pm 8(p=0.005)$} & $p=0.004$ \\
\hline
\end{tabular}

Data are presented as mean \pm SD, unless otherwise stated. RAP: right atrial pressure; $\bar{P}$ pa: mean pulmonary artery pressure; CO: cardiac output; PVR: pulmonary vascular resistance; $\mathrm{Sv}_{\mathrm{O}} \mathrm{O}_{2}$ : mixed venous oxygen saturation. ${ }^{*}: \mathrm{n}=11 ; " \mathrm{n}=13.1 \mathrm{mmHg}=0.133 \mathrm{kPa}$. 

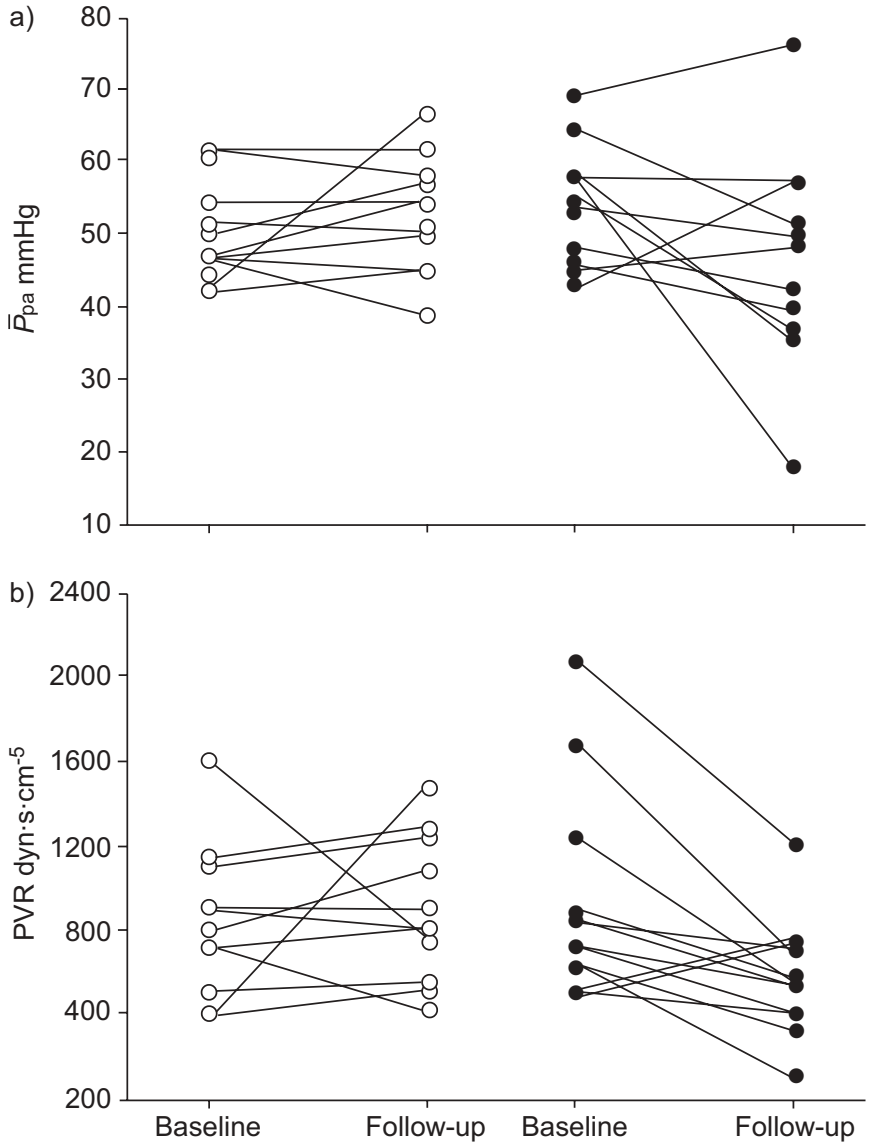

FIGURE 2. Individual haemodynamic response to treatment with inhaled iloprost $(\bigcirc)$ or bosentan $(\bullet)$, expressed as change from baseline to first follow-up measurement of a) mean pulmonary arterial pressure ( $\left.\bar{P}_{\mathrm{pa}}\right)$ and b) pulmonary vascular resistance (PVR). a, b) $n=11$ in iloprost group and $n=13$ in bosentan group.

baseline and $\mathrm{p}=0.233$ versus the iloprost group). This effect was partly lost during further follow-up, but in the 10 patients for whom data were available at the end of the 3-yr follow-up period, 6-min walk distance was still significantly higher than at baseline $(403 \pm 59$ versus $358 \pm 75 \mathrm{~m} ; \mathrm{p}=0.049)$.

\section{Safety}

Inhaled iloprost was well tolerated by all patients and was not associated with any side-effects, except for mild flushing, headaches and coughing. Two patients deteriorated from Child class A to Child class B with no apparent relationship to iloprost treatment.

Bosentan was also well tolerated by the majority of patients. In one patient, hepatic aminotransferases increased to more than three times the upper level of normal but normalised when the bosentan dose was reduced from $125 \mathrm{mg}$ b.i.d. to $62.5 \mathrm{mg}$ b.i.d. Dose reduction, however, resulted in clinical worsening, but the patient improved after addition of sildenafil. No other patient had aminotransferase elevations of more than three times the upper limit of normal. Bilirubin levels at baseline and after 1, 2 and 3 yrs of follow-up were $26 \pm 16,26 \pm 17,24 \pm 12$ and $24 \pm 11 \mu \mathrm{mol} \cdot \mathrm{L}^{-1}$, respectively, and MELD scores were $10 \pm 3,10 \pm 3,10 \pm 2$ and $9 \pm 2$, respectively. As noted above, one patient in the bosentan group died from progressive liver failure, which was believed to be due to progression of the underlying disease and unrelated to bosentan treatment, since aminotransferase levels remained normal throughout treatment.

\section{DISCUSSION}

In the present case series, patients with PPHT treated with bosentan had a better outcome than patients treated with inhaled iloprost. Although disease severity at baseline as determined by 6-min walk distance and haemodynamic variables did not differ between both groups, survival rates at 1, 2 and 3 yrs were 94, 89 and $89 \%$, respectively, in the bosentan group, and 77, 62 and $46 \%$, respectively, in the iloprost group; a difference that was statistically significant. The mortality rates in the iloprost group were similar to those reported from case series of patients with PPHT who did not receive targeted treatment for pulmonary hypertension $[3,4]$, and right heart failure was by far the most common cause of death. Thus, it is possible that bosentan treatment, but not iloprost treatment, improves survival in this patient population, although further data are needed to confirm this hypothesis.

What are the explanations for this observation? Most importantly, haemodynamic improvement was substantially stronger in the bosentan group than in the iloprost group. At the time of the first haemodynamic reassessment (after $8 \pm 4$ months in the iloprost group and after $10 \pm 5$ months in the bosentan group), haemodynamics were practically unchanged in the iloprost group, where the pulmonary vascular resistance had slightly increased from baseline. Some recent studies with inhaled iloprost in other forms of PAH have also failed to demonstrate a substantial haemodynamic improvement, especially when haemodynamics were not assessed immediately after inhalation [14-16]. In contrast, all relevant haemodynamic variables improved in the bosentan group, with a $37 \%$ drop from baseline in the pulmonary vascular resistance, similar to what has been reported in patients with HIV-associated PAH treated with bosentan $(-43 \%)$ [17]. These differences in the haemodynamic response to treatment could explain the more profound and more sustained improvement in exercise capacity, as well as the better survival of the bosentan-treated patients. However, these results have to be interpreted with caution, since haemodynamics were measured at different time-points and not in all patients.

There is a rapidly increasing number of case reports and case series suggesting safety and efficacy of bosentan treatment in patients with PPHT [7, 8, 18-22]. Evidence from experimental work, as well as from histopathological and clinical studies, has shown that endothelin-1 (ET-1) plays a pathogenetic role in several forms of pulmonary hypertension including idiopathic PAH (IPAH) [23, 24] and chronic thromboembolic pulmonary hypertension [25]. It has also been shown that cirrhotics with PPHT have significantly higher ET-1 plasma levels than cirrhotics without this complication, and it has been suggested that ET-1 may be directly involved in the pathogenesis of PPHT [26]. Although it is most unlikely that ET-1 is the only pathogenetic factor involved in the development of PPHT, the therapeutic effects of endothelin receptor blockade support the concept of ET-1 being an important mediator in this condition. 
In addition, the present data provides important safety information. The use of bosentan in patients with PPHT has been questioned, since bosentan has a well-known hepatotoxic potential and aminotransferase elevations have been reported in $7-12 \%$ of patients exposed to this drug $[27,28]$. However, these aminotransferase elevations are reversible and bosentan has not been associated with serious or permanent liver damage. The present study supports the notion that bosentan may also be safe in patients with PPHT, even when treatment periods are extended up to 3 yrs. Nevertheless, it is important to note that all patients who received bosentan in the present series had well preserved liver function and were in Child class A. One recently published case report suggests that bosentan may also be safe and effective in selected patients with more advanced liver dysfunction [29], but it needs to be kept in mind that the drug is not approved for patients with Child class B or C cirrhosis, and that other treatment options, such as sildenafil or intravenous prostacyclin, are available for these patients, and that these options may be safer in patients with advanced liver disease. It will also be important to study the novel endothelin receptor antagonists sitaxsentan and ambrisentan in patients with PPHT, especially since these compounds have distinct receptor affinities and may exert different profiles regarding safety and efficacy in this group of patients.

The question why the results were less favourable with inhaled iloprost is difficult to answer. Iloprost treatment caused temporary improvement in exercise capacity, but this effect was not sustained in the majority of the patients. Furthermore, as outlined above, reassessment by right heart catheterisation after $8 \pm 4$ months of treatment did not show significant haemodynamic improvement. Noncompliance cannot be ruled out in the group treated with nebulised iloprost, and might explain the observed differences in outcome, as the regular usage of the nebulisers was not monitored. Although inhaled iloprost has been in clinical use for almost $10 \mathrm{yrs}$, data supporting the long-term efficacy of this treatment are sparse, and a recent paper by OPITZ et al. [16] has questioned the overall efficacy of this treatment in patients with IPAH. To the best of the present authors' knowledge, long-term treatment results with inhaled iloprost in patients with PPHT have not been published.

The present study had the following limitations. 1) The number of patients was small (although the present series represents the largest population of patients with PPHT studied so far). 2) The patients were not randomised (but most of the baseline variables were well matched, although there was a nonsignificant trend toward more severe liver disease in the iloprost group which may have contributed to the worse outcome in this group). 3) There was no formal study protocol and thus assessments were not carried out at the same time-points and were not complete. 4) Treatments were not blinded (single randomised, controlled or blinded studies have not been performed in the present patient population). Given the small sample sizes and the lack of randomisation, the possibility remains that patients in the iloprost group had a more progressive nature of their disease resulting in poorer response to treatment and poorer outcome, and significant bias affecting the results cannot be excluded. Finally, the impact of treatment on portal hypertension was not investigated; this will be an important issue for future studies, especially since two case reports have described reduction of portal venous pressure with bosentan treatment [8, 20]. Despite these limitations, the current authors feel that the present data provide an important signal, and head-to-head efficacy studies not only for PPHT but also for other forms of $\mathrm{PAH}$ are called for.

In conclusion, the present study provides preliminary evidence that bosentan is a safe and effective treatment for patients with Child A cirrhosis and severe portopulmonary hypertension, whereas the long-term efficacy of inhaled iloprost in this patient population is questionable. Further studies are required to confirm these findings.

\section{REFERENCES}

1 Hoeper MM, Krowka MJ, Strassburg CP. Portopulmonary hypertension and hepatopulmonary syndrome. Lancet 2004; 363: 1461-1468.

2 Halank M, Ewert R, Seyfarth HJ, Hoeffken G. Portopulmonary hypertension. J Gastroenterol 2006; 41: 837-847.

3 Herve P, Lebrec D, Brenot F, et al. Pulmonary vascular disorders in portal hypertension. Eur Respir J 1998; 11: 1153-1166.

4 Robalino BD, Moodie DS. Association between primary pulmonary hypertension and portal hypertension: analysis of its pathophysiology and clinical, laboratory and hemodynamic manifestations. J Am Coll Cardiol 1991; 17: 492-498.

5 McLaughlin VV, Genthner DE, Panella MM, Hess DM, Rich S. Compassionate use of continuous prostacyclin in the management of secondary pulmonary hypertension: a case series. Ann Intern Med 1999; 130: 740-743.

6 Reichenberger F, Voswinckel R, Steveling E, et al. Sildenafil treatment for portopulmonary hypertension. Eur Respir J 2006; 28: 563-567.

7 Hoeper MM, Halank M, Marx C, et al. Bosentan therapy for portopulmonary hypertension. Eur Respir J 2005; 25: 502-508.

8 Halank M, Miehlke S, Hoeffken G, Schmeisser A, Schulze M, Strasser RH. Use of oral endothelin-receptor antagonist bosentan in the treatment of portopulmonary hypertension. Transplantation 2004; 77: 1775-1776.

9 Hoeper MM, Markevych I, Spiekerkoetter E, Welte T, Niedermeyer J. Goal-oriented treatment and combination therapy for pulmonary arterial hypertension. Eur Respir J 2005; 26: 858-863.

10 Halank M, Marx C, Miehlke S, Hoeffken G. Use of aerosolized inhaled iloprost in the treatment of portopulmonary hypertension. J Gastroenterol 2004; 39: 1222-1223.

11 Kamath PS, Wiesner RH, Malinchoc M, et al. A model to predict survival in patients with end-stage liver disease. Hepatology 2001; 33: 464-470.

12 Wiesner RH, McDiarmid SV, Kamath PS, et al. MELD and PELD: application of survival models to liver allocation. Liver Transpl 2001; 7: 567-580.

13 Rodriguez-Roisin R, Krowka MJ, Herve P, Fallon MB. Pulmonary-Hepatic vascular Disorders (PHD). Eur Respir J 2004; 24: 861-880.

14 Olschewski H, Simonneau G, Galie N, et al. Inhaled iloprost for severe pulmonary hypertension. $N$ Engl J Med 2002; 347: 322-329. 
15 McLaughlin VV, Oudiz RJ, Frost A, et al. Randomized study of adding inhaled iloprost to existing bosentan in pulmonary arterial hypertension. Am J Respir Crit Care Med 2006; 174: 1257-1263.

16 Opitz CF, Wensel R, Winkler J, et al. Clinical efficacy and survival with first-line inhaled iloprost therapy in patients with idiopathic pulmonary arterial hypertension. Eur Heart J 2005; 26: 1895-1902.

17 Sitbon O, Gressin V, Speich R, et al. Bosentan for the treatment of human immunodeficiency virus-associated pulmonary arterial hypertension. Am J Respir Crit Care Med 2004; 170: 1212-1217.

18 Molnar C, Alber H, Colleselli D, Vogel W, Kahler CM. Successful switch from inhalative iloprost to oral bosentan in portopulmonary hypertension associated with liver cirrhosis. Wien Klin Wochenschr 2004; 116: 627-630.

19 Grander W, Eller P, Fuschelberger R, Tilg H. Bosentan treatment of portopulmonary hypertension related to liver cirrhosis owing to hepatitis C. Eur J Clin Invest 2006; 36: Suppl. 3, 67-70.

20 Hinterhuber L, Graziadei IW, Kahler CM, Jaschke W, Vogel W. Endothelin-receptor antagonist treatment of portopulmonary hypertension. Clin Gastroenterol Hepatol 2004; 2: 1039-1042.

21 Neuhofer W, Gulberg V, Gerbes AL. Endothelin and endothelin receptor antagonism in portopulmonary hypertension. Eur J Clin Invest 2006; 36: Suppl. 3, 54-61.
22 Stahler G, von Hunnius P. Successful treatment of portopulmonary hypertension with bosentan: case report. Eur J Clin Invest 2006; 36: Suppl. 3, 62-66.

23 Giaid A, Yanagisawa M, Langleben D, et al. Expression of endothelin-1 in the lungs of patients with pulmonary hypertension. N Engl J Med 1993; 328: 1732-1739.

24 Rubens C, Ewert R, Halank M, et al. Big endothelin-1 and endothelin-1 plasma levels are correlated with the severity of primary pulmonary hypertension. Chest 2001; 120: 1562-1569.

25 Bauer M, Wilkens H, Langer F, Schneider SO, Lausberg H, Schafers HJ. Selective upregulation of endothelin B receptor gene expression in severe pulmonary hypertension. Circulation 2002; 105: 1034-1036.

26 Benjaminov FS, Prentice M, Sniderman KW, Siu S, Liu P, Wong F. Portopulmonary hypertension in decompensated cirrhosis with refractory ascites. Gut 2003; 52: 1355-1362.

27 Rubin LJ, Badesch DB, Barst RJ, et al. Bosentan therapy for pulmonary arterial hypertension. N Engl J Med 2002; 346: 896-903.

28 Humbert M, Segal ES, Kiely DG, Carlsen J, Schwierin B, Hoeper MM. Results of European post-marketing surveillance of bosentan in pulmonary hypertension. Eur Respir J 2007; 30: 338-344.

29 Barth F, Gerber PJ, Reichen J, Dufour JF, Nicod LP. Efficiency and safety of bosentan in child $C$ cirrhosis with portopulmonary hypertension and renal insufficiency. Eur J Gastroenterol Hepatol 2006; 18: 1117-1119. 